\title{
COGNITION AND SUICIDE: EFFECTIVENESS OF COGNITIVE BEHAVIOUR THERAPY
}

\author{
Dr. Lence Miloseva, Faculty of Medical Science, Goce Delcev University, Štip, Republic of Macedonia \\ E-mail: lence.miloseva@ugd.edu.mk \\ MD Vladimir Milosev, Clinical Hospital, Štip, Republic of Macedonia \\ E-mail: vlmilos@gmail.com \\ Dr. Kneginja Rihter, Technical University Georg Simon Ohm, Private Paracelsus Medical University, \\ Nuremberg, Germany \\ E-mail: kneginja.richter@gmx.de
}

\author{
A R T I C L E I N F O \\ Studies and Articles \\ Received: May, 17.2016. \\ Revised: June, 05.2016. \\ Accepted: June, 10.2016. \\ doi:10.5937/IJCRSEE1601079M \\ UDK \\ 616.89-008.441.44-085:159.9.019.4
}

Keywords:

cognition,

suicide,

cognitive behavior,

psychotherapy,

effectiveness.

\begin{abstract}
A B S T R A C T
The aim of this review paper is to show an overview of the empirical evidence of effectiveness of cognitive behavioral therapy (CBT) in reducing suicidal cognitions and suicidal behavior. The topic of suicidal cognition and suicidal behavior is of special importance to clinicians and practitioners. Analyses of empirical findings from the oldest, first systematic review and meta-analysis and the newest one shown that there not enough evidence from clinical trials to suggest that CBT focusing on mental illness reduces suicidal cognitions and behaviors. But, from the other hand, CBT focusing on suicidal cognitions and suicidal behaviors was found to be effective. Taking into consideration the effectiveness of this psychotherapy, we can conclude that it is preferable for clinicians to be trained in working with CBT techniques focused on suicidal cognition and behavior that are independent of treatment of mental disorders. In addition, it is necessary to initiate new research that will make it possible to create preventive and interventional programs dedicated to reducing the risk of suicide.
\end{abstract}

(C) 2016 IJCRSEE. All rights reserved.

\section{INTRODUCTION}

According to WHO's report (2014), suicide is the $15^{\text {th }}$ leading cause of death worldwide, accounting for $1.4 \%$ of all deaths, and the second leading cause of death among 15-29 year olds globally. Mental disorders is one of the strongest risk factors for suicide, having been implicated in $91 \%$ of completed suicides (Cavanagh, Carson, Sharpe and Lawrie, 2003). According to Chesney, Goodwin, and Fazel (2014) the risk of suicide is highest among those with borderline personality disorders, followed by depression, bipolar disorder, opioid use and schizophrenia.

According to Mewton and Andrews (2016) CBT is an umbrella term for various

Corresponding Author

Dr. Lence Miloseva, Faculty of Medical Science, Goce Delcev University, Štip, Republic of Macedonia E-mail: lence.miloseva@ugd.edu.mk

\section{(i)}

This work is licensed under a Creative Commons Attribution 4.0 International license. The article is published with Open Access at www.ijcrsee.com treatments that focus on challenging cognitive biases (through cognitive restructuring) and behaviors (through graded exposure and relaxation training).

In the last 30 years, there has been a significant development in cognitive-behavioral models of researching cognitive aspects of suicidality and its treatments. Ellis (1986) is among the first who tried to summarized research on cognitive characteristics of suicidal individuals and who recommended that additional efforts need to be made in developing strategies specifically designed to reduce cognitive vulnerability to suicidal ideation and behavior.

There a few studies with antidepressant trials which shown that reduction of suicidal risk and suicidal behavior with antipsychotic therapy is debatable (Cipriani, Hawton, Stockton, Geddes, 2013). Whether psychotherapy is effective in reducing suicidal risk and suicidal behavior is of special importance for us as clinicians and practitioners.

Tarrier, Taylor and Gooding (2008) claim that psychotherapies, including cognitive behavior (CBT) and dialectical behavior therapy (DBT), have not been shown to im- 
prove suicidal outcomes when mental illness is the main treatment focus. But, on the other hand, based on empirical evidence, both CBT and DBT have been shown to be effective in reducing suicidal risk when these treatments focus on suicidal cognitions and behaviors (Comtois and Linehan, 2006; Tarrier, Taylor and Gooding, 2008). With other words, we can expect better patients outcomes when psychotherapy focuses on suicidal cognitions and suicidal behaviors as dysfunctional personal factors rather than symptoms of mental illness (Linehan, 2008).

When it comes to the CBT approach to suicidal thinking and behavior in depression, it should be noted that first the therapist must determine which problem the suicidal person would solve and then what is the motive of the individual for choosing suicide. In addition, the answer of whether suicide is preferred to a desire to run away from the pain or whether changes need to be made in relations or surroundings of the individual, or both.

When the therapist believes they can understand the client's logic, the therapist could inform them that they could have come to the same conclusions under similar circumstances. The function of this answer would be to help in normalizing the client's experience. Then the therapist must offer the client hope by emphasizing that there are solutions or partial solutions that the client could look into, and then the alternatives to suicide will appear. In order to be involved, it is important that the client believes that the therapist understands their logic and perspective without judgment.

When this transfer is successfully established, the client's task would be to understand the inner, outer and/or thematic triggers of suicidal cognition and behavior, as well as the factors that help in perseverance of suicidal risk (Matthews, 2013).

The therapist's next step in order to help the client would be causing distortions and misconceptions, including core beliefs, that would hinder motivation and make it inefficient in solving problems. Previously, the therapist had done an analysis "for and against" suicide and on the positive and negative reinforces for suicide with the client. The negative reinforces will motivate the client in thinking about reasons to live and not choose suicide, while positive reinforces will help the client determine the alternatives to suicide. In addition, identifying alternatives to suicide also helps begin the task of solving the problem.

It is recommended to argue the "for and against" of every alternative. Then, after the best alternative has been found, the client develops an action plan, which motivates them to follow the results by assessment of the outcomes. The active problem solving by the client would be in function of developing selfefficacy and reducing feelings of helplessness and worthlessness, as well as reducing stress levels by accepting emotional and/or physical pain.

The final phase of the CBT treatment is focused on relapse prevention. In the phase, the client has the opportunity to demonstrate the skills they have learned in the course of the treatment, while the therapist has the chance to assess the adequate application (Matthews, 2013).

\section{THE CURENT REVIEW}

The aim of this systematic review study is to show an overview of the empirical evidence of effectiveness of cognitive behavioral therapy (CBT) in reducing suicidal cognitions and suicidal behavior.

The first systematic review and metaanalysis of CBT and the prevention of suicidal behaviors was performed by Tarrier et al, (2008). They performed a meta-analysis on 28 select studies (based on quality and using CTAM) in order to investigate whether CBT reduced future suicidal behavior. The PsychInfo and Web of Science databases were searched for articles reporting clinical trials from 1980. From 123 potential articles, 28 studies met the entry criteria. The diagnostic categories were broad across the 28 studies and not limited to depression.

Overall, Tarrier et al. found that there was a highly significant effect for CBT in reducing suicide behavior. They concluded that CBT was highly effective in reducing suicidal behaviors within the 3 month period post treatment (combined Hedge's $\mathrm{g}=-.59$, $\mathrm{Z}=-5.26, \mathrm{p}<.0001,95 \% \mathrm{CI}=-.811$ to -.371$)$. Subgroup analysis of CBT demonstrated a significant treatment effect for CBT when: compared to minimal treatment or treatment as usual (but not when compared to another active treatment); for individual treatments (but not group); for adult samples (but not adolescents); treatment directed towards reducing suicidal behavior rather than associated symptoms like depression and reductions in hopelessness. Regarding limitation of the study, authors are cautious in their conclusions because of publication biases.

In recent years, the focus of clinicians 
has been toward improving the assessment of suicidal cognitions and behavior and the possibility of their application in studies regarding suicide.

According to the psychological model of cognitive vulnerability, suicidal cognitions and behaviors exist along a continuum of severity. According to Tarrier, Taylor and Gooding (2008) regarding to severity, these cognitions and behaviors adduce a degree of suicide risk and constitute targets for treatments.

Christensen, Calear, Van Spijker et al. (2014) was searching published articles in publicly available database focusing on psychosocial interventions in general for suicidal ideations, plan and attempts. They succeed to identified 154 randomized controlled trials that assessed suicidal cognitions or behaviors as an outcome measure.

The newest systematic review and metaanalysis with focus on effectiveness of cognitive behavior therapy in reducing suicidal cognitions and behavior in adult population was performed by Mewton and Andrews (2016). The studies included in this review were identified through PsychInfo database, which was searched from 1980 to 2015 using the terms from the previous mentioned study of Tarrier et al, (2008). Authors identified 15 randomized controlled trials of CBT for adults (aged 18 years and older) that included suicide -related cognitions or behaviors as an outcome measure. All 15 articles have in focus suicide cognitions and behavior as a central elements that CBT seek to change. From the evidence of this review CBT has been shown to be effective in reducing the symptoms of mental illnesses that are associated with an increased risk of suicide (Butler, Chapman, Forman and Beck, 2006).

\section{RESULTS AND FINDINGS}

Ten of the 15 included studies in this systematic review measured suicidal cognitions (Weinberg, Gunderson, Hennen, and Cutter, 2006; de Groot et al, 2007; Slee, Garnefski, van der Leeden, Arensman and Spinhoven, 2008; Gandy, Sharpe, Nicholson et al., 2014; Morley, Sitharthan, Haber, Tucker and Sitharthan, 2014; Tarrier, Kelly and Maqsood, 2014; van Spijker, van Straten and Kerkhof, 2014; Wagner, Horn and Maercker, 2014; Weitz, Hollon, Kerkohof and Cuijpers, 2014; Rudd, Bryan, Wertenberger et al., 2015) and there were a total of 17 comparisons with suicidal cognitions aa the outcome of interest.
When suicidal cognitions were the outcome of interest, there were four medium effect size in favor of CBT.

Eight of the 15 included studies measured suicidal behaviors, (Tyrer, Thompson, Schmidt et al. 2003; Brown et al., 2005; Weinberg, Gunderson, Hennen and Cutter, 2006; Slee, Garnefski, van der Leeden, Arensman and Spinhoven, 2008; Cottraux, Boutitie, Milliery et al. 2009; Davidson, Tyrer, Norrie, Palmer and Tyrer, 2010; Barrowclough, Haddock, Wykes et al, 2010; Rudd, Bryan, Wertenberger et al., 2015) and there were a total of 14 comparisons with suicidal behaviors as the outcome of interest. When suicidal behaviors were the outcome of interest, there were three medium efect sizes in favor of CBT.

Seven of the 15 included studies focused on suicidal cognitions or behaviors as the main intervention focus (Tyrer, Thompson, Schmidt et al., 2003; Brown et al., 2005; Weinberg, Gunderson, Hennen and Cutter, 2006; Slee, Garnefski, van der Leeden, Arensman and Spinhoven, 2008; Rudd, Bryan, Wertenberger et al., 2015; Tarrier, Kelly, Maqsood et al., 2014; van Spijker, van Straten, Kerkohof, 2014). It is interesting that strongest effect sizes were drawn out from interventions that focused specifically on suicidal cognitions and behaviors.

\section{DISSCUSION AND CONCLUSIONS}

This review focused specifically on suicidal cognitions and suicidal behaviors because they are the core elements that CBT seek to change. The conclusion drawn from the empirical evidence is that CBT is useful for prevention and reduction of suicidal cognitions and suicidal behaviors. Large clinical reports have also shown that suicidal cognitions and behaviors reduce significantly following CBT for depression (Mewton and Andrews, 2015).

The topic of suicidal cognition and suicidal behavior is of special importance to clinicians and practitioners. Analyses of empirical findings from the oldest, first systematic review and meta-analysis (Terrier et al., 2008) and the newest one (Mewton and Andrews, 2016) shown that there not enough evidence from clinical trials to suggest that CBT focusing on mental illness reduces suicidal cognitions and behaviors. But, from the other hand, CBT focusing on suicidal cognitions and behaviors was found to be effective. 
Unfortunately, this is the first research project in the Republic of Macedonia that is dedicated to researching the cognitive aspects of suicide and its treatment with cognitivebehavioral therapy with the goal of reducing the risk of suicide and suicidal behavior. The effort should be considered in context of some limitations, primarily concerning methodology, that is the instruments and the samples for the study. Of course, cultural specificities of the countries in which the study is being done should also be taken into consideration.

This assessment work is focused on cognitive behavioral psychotherapy, which is known for its effectiveness in reducing symptoms connected with various mental disorders (Butler, Chapman, Forman and Beck, 2006). Based on empirical evidence, we can conclude that CBT is effective and popular strategy in prevention and reduction of suicidal cognitions and suicidal behaviors.

Taking into consideration the effectiveness of this psychotherapy, we can conclude that it is preferable for clinicians to be trained in working with CBT techniques focused on suicidal cognition and behavior that are independent of treatment of mental disorders. In addition, it is necessary to initiate new research that will make it possible to create preventive and interventional programs dedicated to reducing the risk of suicide.

Also, it is of great importance to further reduce suicide deaths and improve patients outcomes. In doing so, there is a need of creating national strategy which will be supplemented with selective or indicated prevention strategies that target groups or individuals at high risk for suicide.

\section{ACKNOWLEDGMENTS}

This paper is supported and is the part of Goce Delcev University project named Clinically relevant risk factors for suicide: Comparison between clinical group with passive suicidal ideation, active suicidal ideation and without suicidal ideation.

\section{Conflict of interests}

The authors declare no conflict of interest.

\section{REFERENCES}

Barrowclough, C., Haddock, G., Wykes, T., Beardmore, R., Conrod, P., Craig, T., Davies, L., Dunn,G., Eisner, E., Lewis,S., Moring, J., Steel,C., \& Tar- rier, N. (2010). Integrated motivational interviewing and cognitive behavioural therapy for people with psychosis and comorbid substance misuse: randomised controlled trial. BMJ, 341, c6325.

Brown, G. K., Ten Have, T., Henriques, G. R., Xie, S. X., Hollander, J. E., \& Beck, A. T. (2005). Cognitive therapy for the prevention of suicide attempts: a randomized controlled trial. JAMA, 294(5), 563-570.

Butler, A. C., Chapman, J. E., Forman, E. M., \& Beck, A. T. (2006). The empirical status of cognitivebehavioral therapy: a review of meta-analyses. Clinical psychology review, 26(1), 17-31.Cavanagh, J. T., Carson, A. J., Sharpe, M., \& Lawrie, S. M. (2003). Psychological autopsy studies of suicide: a syste-matic review. Psychological medicine, 33(03), 395-405.

Chesney, E., Goodwin, G. M., \& Fazel, S. (2014). Risks of all-cause and suicide mortality in mental disorders: a meta-review. World Psychiatry, 13(2), 153-160.

Christensen, H., Calear, A. L., Van Spijker, B., Gosling, J., Petrie, K., Donker, T., \& Fenton, K. (2014). Psychosocial interventions for suicidal ideation, plans, and attempts: A database of randomised controlled trials.BMC psychiatry, 14(1), 1.

Cipriani, A., Hawton, K., Stockton, S., \& Geddes, J. R. (2013). Lithium in the prevention of suicide in mood dis-orders: updated systematic review and meta-analysis. BMJ, 346, 3646.

Comtois, K. A., \& Linehan, M. M. (2006). Psychosocial treatments of suicidal behaviors: A practice friendly review. Journal of clinical psychology, 62(2), 161-170.

Cottraux, J., Note, I. D., Boutitie, F., Mil-liery, M., Genouihlac, V., Yao, S. N., Note, B., Mollard, E., Bonasse, F., Gaillard, S., Djamoussian, D., Guil-lard Cde, M., Culem, A. \& Gueyffier, F. (2009). Cognitive therapy versus Rogerian supportive therapy in borderline personality disorder. Psycho-therapy and psychosomatics, 78(5), 307-316.

Davidson, K. M., Tyrer, P., Norrie, J., Palmer, S. J., \& Tyrer, H. (2010). Cognitive therapy v. usual treatment for borderline personality disorder: prospective 6-year follow-up. The British Journal of Psychiatry, 197(6), 456-462.

de Groot, M., de Keijser, J., Neeleman, J., Kerkhof, A., Nolen, W., \& Burger, H. (2007). Cognitive behaviour therapy to prevent complicated grief among relatives and spouses bereaved by suicide: cluster randomised con-trolled trial. $B M J$, 334 (7601), 994.

Ellis, T. E. (1986). Toward a cognitive ther-apy for suicidal individuals. Professional Psychology: $R e$ search and Practice, 17(2), 125.

Gandy, M., Sharpe, L., Nicholson Perry, K., Thayer, Z., Miller, L., Boserio, J., \& Mohamed, A. (2014). Cognitive Be-haviour Therapy to Improve Mood in People with Epilepsy: A Randomised Controlled Trial. Cognitive behaviour therapy, 43(2), 153-166.

Linehan, M. M. (2008). Suicide intervention research: a field in desperate need of development. Suicide and Life-Threatening Behavior, 38(5), 483-485.

Matthews, J. D. (2013). Cognitive Beha-vioral Therapy Approach for Suicidal Thinking and Behaviors in Depres-sion. INTECH Open Access Publisher. 
Mewton, L., \& Andrews, G. (2015). Cogni-tive behaviour therapy via the inter-net for depression: A useful strategy to reduce suicidal ideation. Journal of affective disorders, 170, 78-84.

Mewton, L., \& Andrews, G. (2016). Cogni-tive behavioral therapy for suicidal behaviors: improving patient out-comes. Psychology research and behavior management, 9, 21.

Morley, K. C., Sitharthan, G., Haber, P. S., Tucker, P., \& Sitharthan, T. (2014). The efficacy of an opportunistic cog-nitive behavioral intervention pack-age $(\mathrm{OCB})$ on substance use and comorbid suicide risk: A multisite randomized controlled trial. Journal of consulting and clinical psychology, 82(1), 130.

Rudd, M. D., Bryan, C. J., Wertenberger, E. G., Peterson, A. L., Young - McCaughan, S., Mintz, J. Williams, S. R., Arne, K. A., Breitbach, J., Delano, K., Wikinson, E., \& Bruse, T. (2015). Brief cognitive-behavioral therapy effects on posttreatment suicide attempts in a military sample: results of a randomized clinical trial with 2-year follow-up. American journal of psychiatry, 172(5), 441-449.

Slee, N., Garnefski, N., van der Leeden, R., Arensman, E., \& Spinhoven, P. (2008). Cognitive-behavioural in-tervention for self-harm: randomised controlled trial. The British Journal of Psychiatry, 192(3), 202-211.

Tarrier, N., Kelly, J., Maqsood, S., Snelson, N., Maxwell, J., Law, H., Dunn,G., \& Gooding, P. (2014). The cognitive behavioural prevention of suicide in psychosis: a clinical trial. Schizophrenia research, 156(2), 204-210.

Tarrier, N., Taylor, K., \& Gooding, P. (2008). Cognitive-behavioral interventions to reduce suicide behavior a systematic review and meta-analysis. Behavior modification, 32(1), 77-108.

Tyrer, P., Thompson, S., Schmidt, U., Jones, V., Knapp, M., Davidson, K., Cata-lan, J., Airlie, J., Baxter, S., Byford, S., Byrne, G., Cameron, S., Caplan, R., Cooper, S., Ferguson, B., Free-man, C., Frost, S., Godley, J., Greenshields, J., Henderson, J., Holden, N., Keech, P., Kim, L., Logan, K., Manley, C., MacLeod, A., Murphy, R., Patience, L., Ramsay, L., De Munroz, S., Scott, J., Seivewright, H., Sivakumar, K., Tata,P., Thornton, S., Ukoumunne, O.C., \& Wessely, S. (2003). Rando-mized controlled trial of brief cogni-tive behaviour therapy versus treat-ment as usual in recurrent deliberate self-harm: the POPMACT study. Psychological medicine, 33(06), 969-976.

van Spijker, B. A., van Straten, A., \& Kerk-hof, A. J. (2014). Effectiveness of online self-help for suicidal thoughts: Results of a randomised controlled trial. PLOS ONE, 9(2), e90118.

Wagner, B., Horn, A. B., \& Maercker, A. (2014). Internet-based versus face-to-face cognitive-behavioral in-tervention for depression: A randomized controlled non-inferiority trial. Journal of affective disorders, 152, 113-121.

Weinberg, I., Gunderson, J. G., Hennen, J., \& Cutter Jr, C. J. (2006). Manual as-sisted cognitive treatment for delibe-rate self-harm in borderline personal-ity disorder patients. Journal of personality disorders, 20(5), 482.

Weitz, E., Hollon, S. D., Kerkhof, A., \& Cuijpers, P. (2014). Do depression treatments reduce suicidal ideation? The effects of CBT, IPT, pharmacotherapy, and placebo on suicidality. Journal of affective disorders, 167, 98-103.

World Health Organization. (2014). Preventing suicide: A global imperative. World Health Organization. 